\title{
Using physical processes to improve physicochemical and microestructural characteristics of fresh and frozen/thawed sheep milk
}

\author{
Luiza T. P. Falcade*, Nathália S. Carvalho, Alline A. L. Tribst.
}

\begin{abstract}
We acessed the efficacy of stirring (ST), high shear dispersion (HSD) and low (LPH) and high (HPH) pressure homogenization to improves the stability of fresh or frozen/ thawed sheep milk (whole and skimmed). After each process, milk samples were evaluated for color, buffering capacity, soluble calcium, $\mathrm{pH}$, particle size distribution and near infrared backscaterring.
\end{abstract}

\section{Key words:}

sheep milk, physical process for homogenization, frozen milk

\section{Introduction}

In Brazil, the sheep milk production is carried out in smallholdings, in which the milk is accumulated for days until reaches an adequate volume for processing ${ }^{1}$. Milk is commonly frozen to prevent microbial growth. These processes modify milk salt balance and damage fat globules, leading to undesirable changes in the microstructure and physicochemical characteristics of milk. The use of stirring, homogenization and dispersion processes may is an alternative to improve the stability of this milk, reducing the fat globules size and, consequently, avoiding the cream separation. We studied the effectiveness of these methods in improving the stability of fresh and frozen / thawed sheep.

\section{Results and Discussion}

In whole milk, freezing reduced opacity, increased buffering capacity, reduced protein and fat interaction, and modify larger particles, forming a plateau profile in the fat globules distribution. In skim milk, it reduced soluble calcium and increased buffering capacity and sedimentation.

Milk homogeneity and stability was improved for almost all processes (except HSD) due to higher interaction/ aggregation of casein micelles into fat globules and size reduction of these globules. On the other hand, the HSD process increased the sedimentation in skimmed milk and the cream separation in the whole one ${ }^{2}$. These phenomena can possibly be explained by intense physical contact induced by the process amongst milk particles, favoring the agglomeration of fat globules and protein interaction, without particle size reduction effect.

Samples processed by ST and LPH showed similar behavior, with milk opacity increase, changes on buffering capacity, formation of particles of intermediate size (size between expected for casein micelle and fat globule) and higher protein adsorption into globules, leading to lower cream separation and higher stability.

Finally, the $\mathrm{HPH}$ induced the most intense changes in sheep milk, being the only process capable of overcoming the physicochemical changes previously caused by freezing and, consequently, resulting in a similar profile of fresh and frozen/ thawed milk. Processed samples showed higher opacity, intense protein-fat interactions and reduced fat globule size, totally avoiding cream separation.
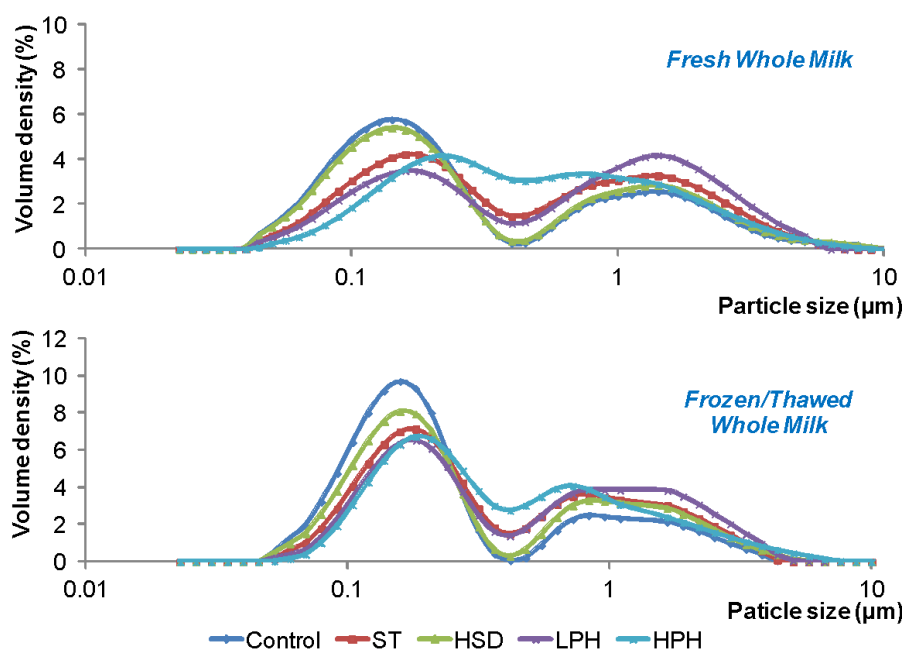

Fig.1. Size distribution and particle parameters of whole sheep milk (fresh and frozen/thawed samples) physically processed by stirring, dispersing and homogenization

\section{Conclusions}

- Freezing changed the buffering capacity and particle size distribution of whole milk and the buffering capacity, sedimentation and soluble calcium in skimmed one;

- Changes caused by the physical processes were more evident in whole milk;

- The physical processes (except HSD) reduced, at least partially, the defects caused by the freezing of the milk, improving the product stability;

- The HPH and LPH also improved the stability of fresh milk;

- In respect to their effectiveness, the processes can be ordered as HPH> LHP> ST;

- Although less effective, the ST can be an interesting alternative to process previously frozen sheep milk, since it is a cheap, simple and easy to operate technology.

\section{Acknowledgement}

To PIBIC and FAPESP (Project 2017/02832-4) for financial support and smallholding Rima for the milk donation.

${ }^{1}$ TRIBST, A. A. L., RIBEIRO, L. R., LEITE JUNIOR, B. R. D. C., DE OLIVEIRA, M. M., CRISTIANINI, M. Fermentation profile and characteristics of yoghurt manufactured from forzen sheep milk. International Dairy Journal, 2018.

${ }^{2}$ TRIBST, A. A. L., FAlCADE, L. T. P., LEITE JUNIOR, B. R. D. C., DE OLIVEIRA, M. M. D. Impact of extended refrigerated storage and freezing/thawing storage combination on physicochemical and microstructural characteristics of raw whole and skimmed sheep milk. International Dairy Journal, 2019 